\title{
High-Selectivity Bandpass Filter Based on Two Merged Ring Resonators
}

\author{
Xiao-yu $W E N G^{1}$, Kai-da XU ${ }^{1,2}$, Ying-jiang $G U O^{3}$, An-xue $Z H A N G^{1}$, Qiang $C H E N^{2}$ \\ ${ }^{1}$ School of Information and Communications Engineering, Xi'an Jiaotong University, Xi' an 710049, China \\ ${ }^{2}$ Dept. of Communications Engineering, Graduate School of Engineering, Tohoku University, Sendai 980-8579, Japan \\ ${ }^{3}$ Microsystem and Terahertz Research Center, China Academy of Engineering Physics, Chengdu 610200, China \\ kaidaxu@ieee.org
}

Submitted January 3, 2021 / Accepted May 29, 2021

\begin{abstract}
A high-selectivity bandpass filter (BPF) based on two merged ring resonators is presented in this paper. The structure of this proposed BPF can be seen as the two one-wavelength ring resonators merged each other by sharing the common $\lambda_{\mathrm{g}} / 2$ microstrip line. Due to symmetric structure, it can be analyzed by even- and odd-mode method and the locations of six transmission zeros are calculated using input impedance deductions. For further demonstration, a BPF example centered at $2 \mathrm{GHz}$ is fabricated with high frequency selectivity. The measured 3-dB fractional bandwidth is $11 \%(1.89-2.11 \mathrm{GHz})$ and insertion loss is less than $2 \mathrm{~dB}$ in the passband. Good agreement between simulation and measurement verifies the feasibility of the design method.
\end{abstract}

\section{Keywords}

Bandpass filter, coupled-line structures, high selectivity, transmission zeros

\section{Introduction}

In the modern wireless communication systems, highperformance bandpass filters (BPFs) with low insertion loss in the passband and high out-of-band suppression are extremely desirable. In recent years, numerous different methods for designing high-performance BPFs have been presented, such as using coupled line structures [1], [2], ring resonators [3], [4], spoof surface plasmon polaritons [5], [6], transversal signal-interference techniques [7]. In [1], a compact seventh-order wideband BPF with sharp roll-off skirts using coupled lines and open/shorted stubs is proposed. The open/shorted stubs are utilized to introduce more transmission zeros (TZs) and acquire better performance in the stopband. In [3], a dual-mode ring resonator fed by quarter-wavelength side-coupled lines is analyzed. The resonator synthesis is developed to calculate the center frequency, bandwidth, TZs and insertion loss. In [7], transversal signal-interference concept is utilized that employing two different transmission paths for the BPF. And the TZs were generated when the two paths are out-of-phase. But this method is at the expense of a large circuit size. Besides, several novel structures are introduced to achieve higher performance, such as two pairs of twist modified split-ring resonators [8] and stepped impedance open-stub loaded ring resonator [9].

In this paper, a BPF based on two merged ring resonators with high selectivity is proposed, which is quite different from the BPF using ring resonators in [10]. Due to the symmetric structure of this proposed BPF, the distributions of six TZs can be calculated by odd- and even-mode method. The theoretical derivation of the proposed BPF is demonstrated. For validation, a BPF example centered at $2 \mathrm{GHz}$ is fabricated and measured.

\section{Design and Analysis of the Proposed BPF}

The ideal circuit of the proposed BPF, which consists of two pairs of coupled lines and five microstrip lines, is shown in Fig. 1(a). The filter structure can be seen as the two one-wavelength $\left(\lambda_{\mathrm{g}}\right)$ ring resonators merged each other with $\lambda_{\mathrm{g}} / 2$ merged length in the middle and $\lambda_{\mathrm{g}} / 4$ coupled to input and output feedlines. Due to symmetry of this BPF structure, it can be analyzed by even- and odd-mode equivalent circuits as illustrated in Fig. 1(b) and (c), respectively.

Observed from Fig. 1(b), the following equation can be established [11],

$$
\left[\begin{array}{c}
V_{1}^{\mathrm{e}} \\
V_{2}^{\mathrm{e}} \\
V_{3}^{\mathrm{e}} \\
V_{4}^{\mathrm{e}} \\
V_{5}^{\mathrm{e}} \\
V_{6}^{\mathrm{e}}
\end{array}\right]=\left[\begin{array}{ll}
{[\mathbf{Z}]^{\mathrm{a}}} & \\
& {[\mathbf{Z}]^{\mathrm{b}}}
\end{array}\right] \cdot\left[\begin{array}{c}
I_{1}^{\mathrm{e}} \\
I_{2}^{\mathrm{e}} \\
I_{3}^{\mathrm{e}} \\
I_{4}^{\mathrm{e}} \\
I_{5}^{\mathrm{e}} \\
I_{6}^{e}
\end{array}\right]
$$

where $[\mathbf{Z}]^{\mathrm{a}}$ and $[\mathbf{Z}]^{\mathrm{b}}$ denote $4 \times 4$ and $2 \times 2$ impedance matrices of the circuit network in dash box, $V_{n}^{\mathrm{e}}$ and $I_{n}^{\mathrm{e}}$ denote the voltage and current of the corresponding $n$th port, respectively. 


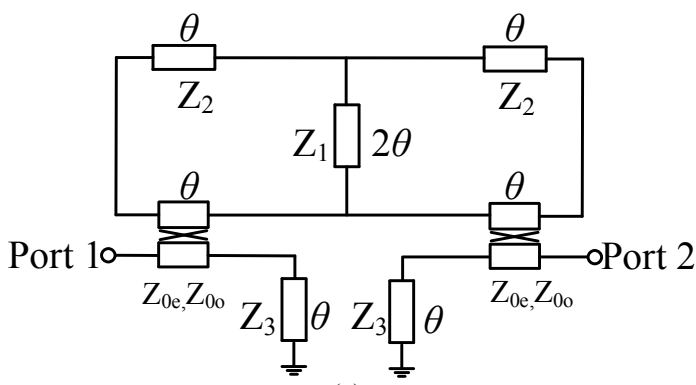

(a)

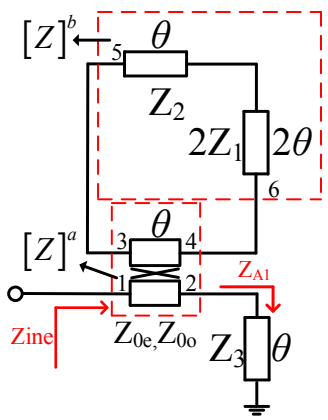

(b)

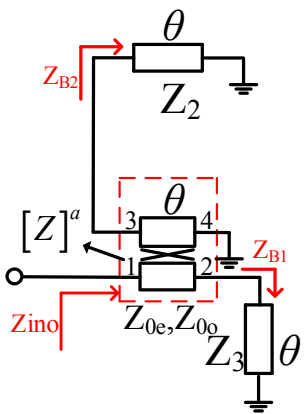

(c)
Fig. 1. (a) Ideal circuit model of the proposed BPF and its (b) even-mode equivalent circuit, and (c) odd-mode equivalent circuit, where $\theta=90^{\circ}$.

The impedance matrix of the coupled line $[\mathbf{Z}]^{\mathrm{a}}$ can be expressed by

$$
[\mathbf{Z}]^{\mathrm{a}}=\left[\begin{array}{cccc}
Z_{11}^{\mathrm{a}} & Z_{12}^{\mathrm{a}} & Z_{13}^{\mathrm{a}} & Z_{14}^{\mathrm{a}} \\
Z_{21}^{\mathrm{a}} & Z_{22}^{\mathrm{a}} & Z_{23}^{\mathrm{a}} & Z_{24}^{\mathrm{a}} \\
Z_{31}^{\mathrm{a}} & Z_{32}^{\mathrm{a}} & Z_{33}^{\mathrm{a}} & Z_{34}^{\mathrm{a}} \\
Z_{41}^{\mathrm{a}} & Z_{42}^{\mathrm{a}} & Z_{43}^{\mathrm{a}} & Z_{44}^{\mathrm{a}}
\end{array}\right]
$$

where

$$
\begin{aligned}
& Z_{11}^{\mathrm{a}}=Z_{22}^{\mathrm{a}}=Z_{33}^{\mathrm{a}}=Z_{44}^{\mathrm{a}}=-\mathrm{j} \frac{1}{2}\left(Z_{0 \mathrm{e}}+Z_{0 \mathrm{o}}\right) \cot \theta, \\
& Z_{12}^{\mathrm{a}}=Z_{21}^{\mathrm{a}}=Z_{34}^{\mathrm{a}}=Z_{43}^{\mathrm{a}}=-\mathrm{j} \frac{1}{2}\left(Z_{0 \mathrm{e}}+Z_{0 \mathrm{o}}\right) \csc \theta, \\
& Z_{13}^{\mathrm{a}}=Z_{31}^{\mathrm{a}}=Z_{24}^{\mathrm{a}}=Z_{42}^{\mathrm{a}}=-\mathrm{j} \frac{1}{2}\left(Z_{0 \mathrm{e}}-Z_{0 \mathrm{o}}\right) \cot \theta, \\
& Z_{14}^{\mathrm{a}}=Z_{41}^{\mathrm{a}}=Z_{23}^{\mathrm{a}}=Z_{32}^{\mathrm{a}}=-\mathrm{j} \frac{1}{2}\left(Z_{0 \mathrm{e}}-Z_{0 \mathrm{o}}\right) \csc \theta .
\end{aligned}
$$

On the other hand, the impedance matrix $[\mathbf{Z}]^{\mathrm{b}}$ can be expressed by:

$$
[\mathbf{Z}]^{\mathrm{b}}=\left[\begin{array}{cc}
Z_{11}^{\mathrm{b}} & Z_{12}^{\mathrm{b}} \\
Z_{21}^{\mathrm{b}} & Z_{22}^{\mathrm{b}}
\end{array}\right] .
$$

Seen from Fig. 1(b), the network with impedance matrix $[\mathbf{Z}]^{\mathrm{b}}$ is constituted by two connected microstrip lines. The voltage and current of the two connected microstrip lines can be determined [11]:

$$
\begin{gathered}
{\left[\begin{array}{c}
V_{5}^{\mathrm{e}} \\
V_{\text {node }}
\end{array}\right]=\left[\begin{array}{ll}
-\mathrm{j} Z_{2} \cot \theta & -\mathrm{j} Z_{2} \csc \theta \\
-\mathrm{j} Z_{2} \csc \theta & -\mathrm{j} Z_{2} \cot \theta
\end{array}\right]\left[\begin{array}{c}
I_{5}^{\mathrm{e}} \\
I_{\text {node }}
\end{array}\right],} \\
{\left[\begin{array}{c}
V_{\text {node }} \\
V_{6}^{\mathrm{e}}
\end{array}\right]=\left[\begin{array}{ll}
-\mathrm{j} 2 Z_{1} \cot 2 \theta & -\mathrm{j} 2 Z_{1} \csc 2 \theta \\
-\mathrm{j} 2 Z_{1} \csc 2 \theta & -\mathrm{j} 2 Z_{1} \cot 2 \theta
\end{array}\right]\left[\begin{array}{c}
-I_{\text {node }} \\
I_{6}^{\mathrm{e}}
\end{array}\right]}
\end{gathered}
$$

where $V_{\text {node }}$ denotes the voltage of the connection node, $I_{\text {node }}$ denotes the current of the connection node, the opposite sign of $I_{\text {node }}$ in (3c) is due to the opposite current direction with the definition of impedance matrix.

Therefore, the impedance matrix $[\mathbf{Z}]^{\mathrm{b}}$ can be obtained by combining ( $3 \mathrm{~b})$ and (3c) to eliminate $V_{\text {node }}$ and $I_{\text {node }}$. The elements of $[Z]^{\mathrm{b}}$ are shown as follows:

$$
\begin{gathered}
Z_{11}^{\mathrm{b}}=\mathrm{j}\left(\frac{Z_{2}^{2} \csc ^{2} \theta}{Z_{2} \cot \theta+2 Z_{1} \cot 2 \theta}-Z_{2} \cot \theta\right), \\
Z_{12}^{\mathrm{b}}=Z_{21}^{\mathrm{b}}=-\mathrm{j}\left(\frac{2 Z_{1} Z_{2} \csc \theta \csc 2 \theta}{Z_{2} \cot \theta+2 Z_{1} \cot 2 \theta}\right), \\
Z_{22}^{\mathrm{b}}=\mathrm{j}\left(\frac{4 Z_{1}^{2} \csc ^{2} 2 \theta}{Z_{2} \cot \theta+2 Z_{1} \cot 2 \theta}-2 Z_{1} \cot 2 \theta\right) .
\end{gathered}
$$

According to the definition of impedance matrix [9], it can be obtained that $V_{2}^{\mathrm{e}}=-Z_{\mathrm{A} 1} I_{2}^{\mathrm{e}}, V_{3}^{\mathrm{e}}=V_{5}^{\mathrm{e}}, I_{3} \mathrm{e}=-I_{5}$, $V_{4}^{\mathrm{e}}=V_{6}^{\mathrm{e}}, I_{4}{ }^{\mathrm{e}}=-I_{6}{ }^{\mathrm{e}}$ in Fig. 1(b). By substituting the constrain conditions, equation (1) can be simplified as:

$\left[\begin{array}{c}V_{1}^{\mathrm{e}} \\ 0 \\ 0 \\ 0\end{array}\right]=\left[\begin{array}{cccc}Z_{11}^{\mathrm{a}} & Z_{12}^{\mathrm{a}} & Z_{13}^{a} & Z_{14}^{\mathrm{a}} \\ Z_{21}^{\mathrm{a}} & Z_{22}^{\mathrm{a}}+Z_{\mathrm{A} 1} & Z_{23}^{\mathrm{a}} & Z_{24}^{\mathrm{a}} \\ Z_{31}^{\mathrm{a}} & Z_{32}^{\mathrm{a}} & Z_{33}^{\mathrm{a}}+Z_{11}^{\mathrm{b}} & Z_{34}^{\mathrm{a}}+Z_{12}^{\mathrm{b}} \\ Z_{41}^{\mathrm{a}} & Z_{42}^{\mathrm{a}} & Z_{43}^{\mathrm{a}}+Z_{21}^{\mathrm{b}} & Z_{44}^{\mathrm{a}}+Z_{22}^{\mathrm{b}}\end{array}\right]\left[\begin{array}{c}I_{1}^{\mathrm{e}} \\ I_{2}^{\mathrm{e}} \\ I_{3}^{\mathrm{e}} \\ I_{4}^{\mathrm{e}}\end{array}\right]$

$$
=\mathbf{A}\left[\begin{array}{c}
I_{1}^{\mathrm{e}} \\
I_{2}^{\mathrm{e}} \\
I_{3}^{\mathrm{e}} \\
I_{4}^{\mathrm{e}}
\end{array}\right]
$$

where

$$
Z_{\mathrm{A} 1}=\mathrm{j} Z_{3} \tan \theta \text {. }
$$

Consequently, the input impedance of the even-mode equivalent circuit can be derived using inverse matrix [10], as follows:

$$
Z_{\text {ine }}=\frac{V_{1}^{\mathrm{e}}}{I_{1}^{\mathrm{e}}}=\frac{1}{\left(\mathbf{A}^{-1}\right)_{11}}
$$
obtained:

Likewise, the odd-mode input impedance can be also

$$
Z_{\text {ino }}=\frac{V_{1}^{\mathrm{o}}}{I_{1}^{\mathrm{o}}}=\frac{1}{\left(\mathbf{B}^{-1}\right)_{11}}
$$

where 


$$
\begin{gathered}
\mathbf{B}=\left[\begin{array}{cccc}
Z_{11}^{\mathrm{a}} & Z_{12}^{\mathrm{a}} & Z_{13}^{\mathrm{a}} & Z_{14}^{\mathrm{a}} \\
Z_{21}^{\mathrm{a}} & Z_{22}^{\mathrm{a}}+Z_{\mathrm{B} 1} & Z_{23}^{\mathrm{a}} & Z_{24}^{\mathrm{a}} \\
Z_{31}^{\mathrm{a}} & Z_{32}^{\mathrm{a}} & Z_{33}^{\mathrm{a}}+Z_{\mathrm{B} 2} & Z_{34}^{\mathrm{a}} \\
Z_{41}^{\mathrm{a}} & Z_{42}^{\mathrm{a}} & Z_{43}^{\mathrm{a}} & Z_{44}^{\mathrm{a}}
\end{array}\right], \\
Z_{\mathrm{B} 1}=\mathrm{j} Z_{3} \tan \theta, \\
Z_{\mathrm{B} 2}=\mathrm{j} Z_{2} \tan \theta .
\end{gathered}
$$

Therefore, the reflection coefficient $S_{11}$ and transmission coefficient $S_{21}$ of the proposed BPF can be calculated as [11]:

$$
\begin{aligned}
& S_{11}=\frac{\Gamma_{\mathrm{e}}+\Gamma_{\mathrm{o}}}{2}=\frac{Z_{\text {ine }} Z_{\text {ino }}-Z_{0}^{2}}{\left(Z_{\text {ine }}+Z_{0}\right)\left(Z_{\text {ino }}+Z_{0}\right)}, \\
& S_{21}=\frac{\Gamma_{\mathrm{e}}-\Gamma_{\mathrm{o}}}{2}=\frac{Z_{0}\left(Z_{\text {ine }}-Z_{\text {ino }}\right)}{\left(Z_{\text {ine }}+Z_{0}\right)\left(Z_{\text {ino }}+Z_{0}\right)} .
\end{aligned}
$$

Figure 2(a) shows the calculated responses by MATLAB and simulated responses by ADS software of the proposed BPF, where $Z_{0 \mathrm{e}}=185 \Omega, Z_{0 \mathrm{0}}=98 \Omega, Z_{1}=50 \Omega$, $Z_{2}=92 \Omega, Z_{3}=80 \Omega$ and $\theta=90^{\circ}$. The simulation results using ADS agree well with the theoretical deductions. Seen from Fig. 2(a), there are five transmission poles in the passband and six TZs $\left(f_{\mathrm{tz} 1}, f_{\mathrm{tz} 2}, f_{\mathrm{tz} 3}, f_{\mathrm{tz} 4}, f_{\mathrm{tz} z}\right.$, and $\left.f_{\mathrm{tz} 6}\right)$ in the stopband ranging from 0 to $2 f_{0}$, where $f_{0}$ denotes the center frequency of the proposed BPF. These TZs can be determined by setting $S_{21}=0$, and the calculated results are shown below:

$$
\begin{gathered}
f_{\mathrm{tz} 1}=0, f_{\mathrm{tz} 6}=2 f_{0}, \\
f_{\mathrm{tz} 2}=\frac{2 f_{0}}{\pi} \cos ^{-1}\left(\sqrt{Z_{2} Z_{3} \frac{B+\sqrt{C}}{4 A}}\right), f_{\mathrm{tz} 5}=2 f_{0}-f_{\mathrm{tz} 2} \\
f_{\mathrm{tz} 3}=\frac{2 f_{0}}{\pi} \cos ^{-1}\left(\sqrt{Z_{2} Z_{3} \frac{B-\sqrt{C}}{4 A}}\right), f_{\mathrm{tz} 4}=2 f_{0}-f_{\mathrm{tz} 3}
\end{gathered}
$$

where

$$
\begin{aligned}
A= & 8\left(Z_{0 \mathrm{e}}{ }^{2}+Z_{0 \mathrm{o}}{ }^{2}\right)\left(Z_{1}+Z_{2}\right)+4 Z_{2} Z_{0 \mathrm{e}} Z_{0 \mathrm{o}}\left(Z_{1}+Z_{3}\right)\left(Z_{0 \mathrm{e}}+Z_{0 \mathrm{o}}\right) \\
& +4 Z_{2} Z_{3}\left[Z_{1} Z_{3}\left(Z_{0 \mathrm{e}}+Z_{0 \mathrm{o}}\right)-2 Z_{2} Z_{0 \mathrm{e}} Z_{0 \mathrm{o}}+Z_{2} Z_{3}\left(2 Z_{1}+Z_{2}\right)\right] \\
& +Z_{2} Z_{3}\left[Z_{3}\left(Z_{0 \mathrm{e}}+Z_{0 \mathrm{o}}\right)^{2}+2 Z_{1}\left(Z_{0 \mathrm{e}}-Z_{0 \mathrm{o}}\right)^{2}\right],
\end{aligned}
$$$$
B=3\left[\left(Z_{0 \mathrm{e}}+Z_{0 \mathrm{o}}\right)^{2}+4 Z_{2}^{2}\right] Z_{3}
$$$$
+4\left[\left(Z_{0 \mathrm{e}}-Z_{0 o}\right)^{2}+2\left(Z_{0 \mathrm{e}}+Z_{0 \mathrm{o}}\right) Z_{3}\right] Z_{1}
$$$$
+4\left(4 Z_{1}-Z_{0 \mathrm{e}}-Z_{0 \mathrm{o}}\right) Z_{2} Z_{3}+8\left(Z_{0 \mathrm{e}}+Z_{0 \mathrm{o}}-2 Z_{2}\right) Z_{0 \mathrm{e}} Z_{0 \mathrm{o}} \text {, }
$$

$C=D+Z_{3}\left(8 E+16 Z_{2} F\right)-64 \frac{Z_{1}}{Z_{2}}\left[Z_{0 \mathrm{e}} Z_{0 \mathrm{o}}\left(Z_{0 \mathrm{e}}+Z_{0 \mathrm{o}}\right)\right]^{2}$,

$$
\begin{aligned}
D= & \left(4 Z_{1}+Z_{3}\right)^{2}\left(Z_{0 \mathrm{e}}-Z_{0 \mathrm{o}}\right)^{4} \\
& +16\left[8 Z_{1}\left(2 Z_{2}-Z_{3}\right)-Z_{3}^{2}\right]\left(Z_{0 \mathrm{e}} Z_{0 \mathrm{o}}\right)^{2} \\
& -16\left\{4\left[Z_{3}\left(2 Z_{1}+Z_{2}\right)^{2}+2 Z_{1} Z_{2}\left(Z_{2}-Z_{3}\right)\right]\right. \\
& \left.-\left(2 Z_{1}+Z_{3}\right)\left(Z_{0 \mathrm{e}}+Z_{0 \mathrm{o}}\right)^{2}\right\} Z_{0 \mathrm{e}} Z_{0 \mathrm{o}}\left(Z_{0 \mathrm{e}}+Z_{0 \mathrm{o}}\right),
\end{aligned}
$$

$E=$

$\left\{\left(20 Z_{1}+4 Z_{2}+Z_{3}\right) Z_{0 \mathrm{e}} Z_{0 \mathrm{o}}+\left(4 Z_{1}+Z_{3}\right)\left(2 Z_{1}+Z_{2}\right)\left(Z_{0 \mathrm{e}}+Z_{0 \mathrm{o}}\right)\right.$ $\left.+\left[Z_{2}\left(4 Z_{1}+Z_{2}\right)\left(4 Z_{1}+3 Z_{3}\right)+8 Z_{1}^{2} Z_{3}\right]\right\}\left(Z_{0 \mathrm{e}}+Z_{0 \mathrm{o}}\right)^{2}$,

$$
\begin{aligned}
F= & Z_{2} Z_{3}\left(4 Z_{1}+Z_{2}\right)^{2}-8\left(Z_{1}+Z_{2}\right)\left(4 Z_{1}+Z_{2}\right) Z_{0 \mathrm{e}} Z_{0 \mathrm{o}} \\
& +2 Z_{3}\left(2 Z_{1}+Z_{2}\right)\left(4 Z_{1}+Z_{2}\right)\left(Z_{0 \mathrm{e}}+Z_{0 \mathrm{o}}\right) .
\end{aligned}
$$

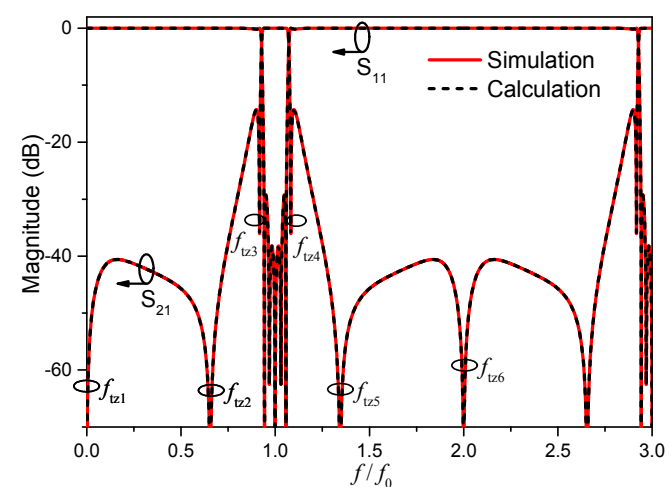

(a)

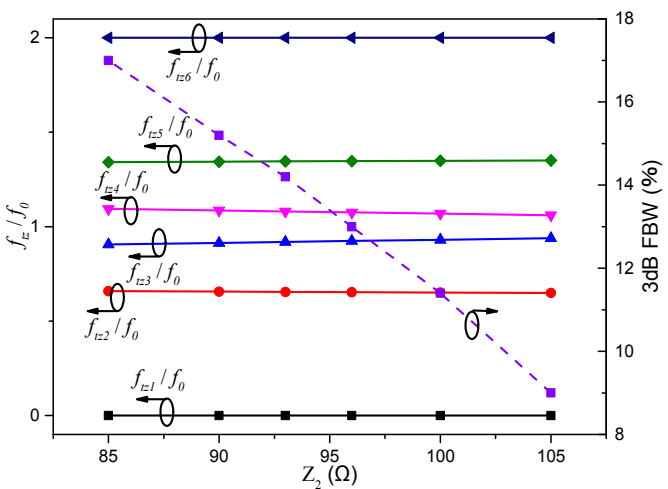

(b)

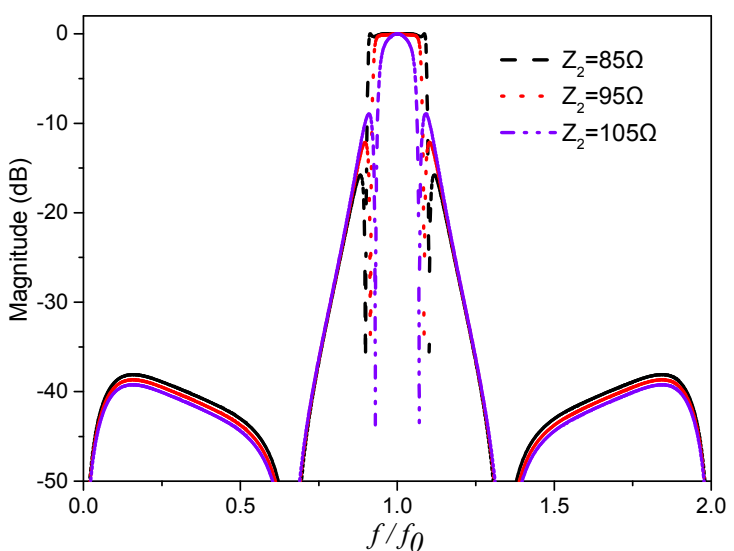

(c) 


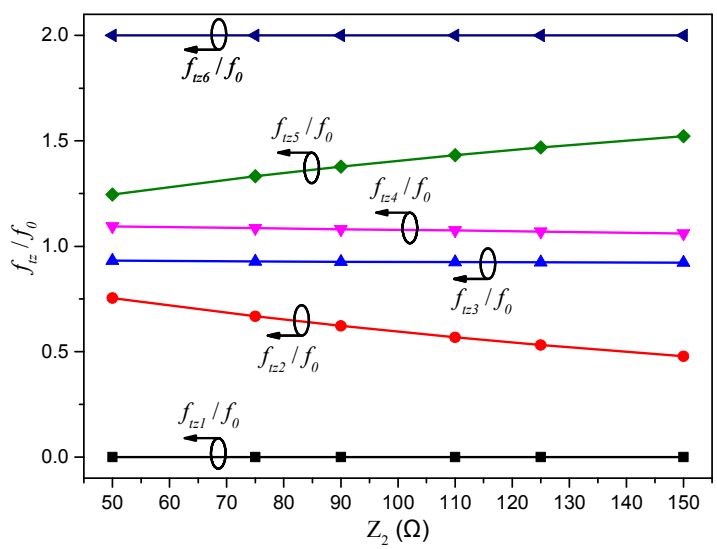

(d)

Fig. 2. (a) Calculated responses by MATLAB and simulated responses by ADS of the proposed BPF, where $Z_{0 \mathrm{e}}=185 \Omega, \quad Z_{0 \mathrm{o}}=98 \Omega, \quad Z_{1}=50 \Omega, \quad Z_{2}=92 \Omega$, $Z_{3}=80 \Omega$, (b) calculated $f_{\mathrm{tz}} / f_{0}$ and the $3-\mathrm{dB}$ FBW versus $Z_{2}$, (c) simulated $S_{21}$ versus $Z_{2}$, where $Z_{0 \mathrm{e}}=185 \Omega, \quad Z_{0 \mathrm{o}}=98 \Omega, \quad Z_{1}=50 \Omega, \quad Z_{3}=80 \Omega$, (d) calculated $f_{\mathrm{tz}} / f_{0}$ versus $Z_{3}$, where $Z_{0 \mathrm{e}}=185 \Omega$, $Z_{0 \mathrm{o}}=98 \Omega, Z_{1}=50 \Omega, Z_{2}=92 \Omega$.

Obviously, the two TZs $f_{\mathrm{tz} 1}$ and $f_{\mathrm{tz} 6}$ are constant, located at 0 and $2 f_{0}$, respectively. When $Z_{0 \mathrm{e}}=185 \Omega$, $Z_{0 \mathrm{o}}=98 \Omega$ and $Z_{1}=50 \Omega$ are fixed, the other $\mathrm{TZs}\left(f_{\mathrm{tz} 2}, f_{\mathrm{tz} 3}\right.$, $\left.f_{\mathrm{tz} 4}, f_{\mathrm{tz} 5}\right)$ are relevant to the characteristic impedances $Z_{2}$ and $Z_{3}$. Figure 2(b) indicates the ratio of $f_{\mathrm{tz}}$ to $f_{0}$ and $3-\mathrm{dB}$ fractional bandwidth (FBW) versus $Z_{2}$. As the characteristic impedance $Z_{2}$ shifts, $f_{\mathrm{tz} 1}$ and $f_{\mathrm{tz} 6}$ keep fixed, $f_{\mathrm{tz} 2}$ and $f_{\mathrm{tz} 4}$ are almost unchanged, whereas $f_{\mathrm{tz} 3}$ and $f_{\mathrm{tz} 4}$ will be adjusted. To illustrate more clearly, the $S_{21}$ simulation results with different values of $Z_{2}$ are shown in Fig. 2(c). It can be seen that the 3-dB FBW will be broadened with the decrease of $Z_{2}$. The minimum $3-\mathrm{dB}$ FBW will be approached when $Z_{2}$ increases to $105 \Omega$ under the rejection condition of over $10 \mathrm{~dB}$ at the stopband. In contrast, as depicted in Fig. 2(d), the locations of $f_{\mathrm{tz} 2}$ and $f_{\mathrm{tz} 5}$ will be moved rather than $f_{\mathrm{tz} 3}$ and $f_{\mathrm{tz} 4}$, as the characteristic impedance $Z_{3}$ is changed.

\section{Implementation Results}

For demonstration, an example of the proposed BPF centered at $2 \mathrm{GHz}$ is designed and fabricated. The physical dimensions of the coupled lines and those of the microstrip lines can be extracted from the corresponding electrical lengths and characteristic impedances. These dimensions of the BPF are further fine-tuned in full-wave electromagnetic simulation software Ansys HFSS to consider the unintended coupling effect. The layout of the proposed filter and its final dimensions are shown in Fig. 3(a). Figure 3(b) illustrates the photograph fabricated on a F4B substrate with relative dielectric constant of $\varepsilon_{\mathrm{r}}=2.65$ and thickness of $h=1 \mathrm{~mm}$. The occupied size of this filter is approximately $49.5 \times 30.5 \mathrm{~mm}^{2}$, i.e., $0.49 \lambda_{\mathrm{g}} \times 0.30 \lambda_{\mathrm{g}}$, where $\lambda_{\mathrm{g}}$ is the guided wavelength of $50 \Omega$ microstrip line at $2 \mathrm{GHz}$.
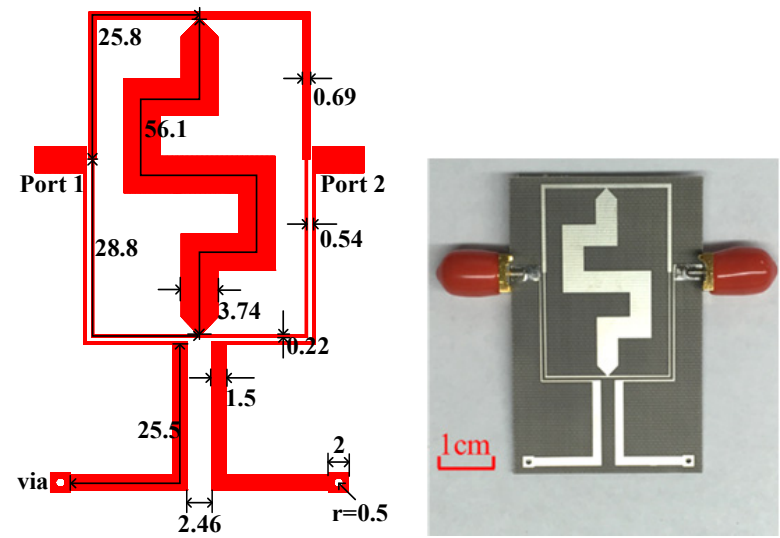

Fig. 3. (a) Layout of the proposed BPF (unit: mm), and (b) its fabricated photograph.

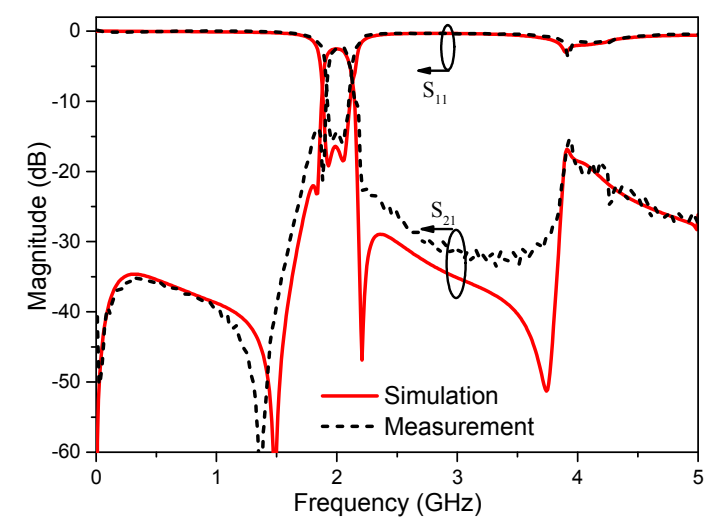

Fig. 4. Simulated and measured S-parameters of the BPF.

\begin{tabular}{|c|c|c|c|c|c|c|c|}
\hline & $\begin{array}{c}f_{0} \\
(\mathrm{GHz})\end{array}$ & $\begin{array}{c}\text { FBW } \\
(\%)\end{array}$ & $\begin{array}{c}\text { Number of } \\
\text { TZs }\end{array}$ & $\begin{array}{c}\text { Insertion / Return Loss } \\
(\mathrm{dB})\end{array}$ & $\begin{array}{c}\text { Relative permittivity and thickness of the } \\
\text { dielectric }\end{array}$ & $\begin{array}{c}\text { Circuit size } \\
\left(\lambda_{0} \times \lambda_{0}\right)\end{array}$ & $\begin{array}{c}\text { Circuit size } \\
\left(\lambda_{\mathrm{g}} \times \lambda_{\mathrm{g}}\right)\end{array}$ \\
\hline$[4]$ & 3.2 & 20.6 & 6 & $2.2 / 12.5$ & $\varepsilon_{\mathrm{r}}=2.65, h=1 \mathrm{~mm}$ & $0.75 \times 0.43$ & $1.06 \times 0.61$ \\
\hline$[8]$ & 2.1 & 19 & 8 & $1.8 / 12$ & $\varepsilon_{\mathrm{r}}=2.65, h=1 \mathrm{~mm}$ & $0.26 \times 0.19$ & $0.39 \times 0.28$ \\
\hline$[13]-\mathrm{I}$ & 4.5 & 60 & 2 & $1.6 / 10$ & $\varepsilon_{\mathrm{r}}=4.4, h=0.8 \mathrm{~mm}$ & $0.18 \times 0.06$ & $0.28 \times 0.09$ \\
\hline$[14]$ & 2.6 & 3 & 1 & $1.8 / 10$ & $\varepsilon_{\mathrm{r}}=10.7, h=1.27 \mathrm{~mm}$ & $0.16 \times 0.09$ & $0.42 \times 0.25$ \\
\hline$[15]$ & 3.35 & 6 & 2 & $2.4 / \mathrm{NM}^{*}$ & $\mathrm{NM}$ & $0.12 \times 0.09$ & \\
\hline$[16]$ & 1.68 & 4 & 2 & $1.3 / 22$ & $\varepsilon_{\mathrm{r}}=10.8, h=1.27 \mathrm{~mm}$ & $0.21 \times 0.63$ & \\
\hline $\begin{array}{c}\text { This } \\
\text { work }\end{array}$ & 2 & 11 & 5 & $2 / 15$ & $\varepsilon_{\mathrm{r}}=2.65, h=1 \mathrm{~mm}$ & $0.330 \times 0.203$ & $0.49 \times 0.30$ \\
\hline
\end{tabular}

Tab. 1. Performance comparisons with some previous BPFs (*NM: Not Mentioned). 
The simulated and measured $S_{11}$ and $S_{21}$ are shown in Fig. 4, which agree reasonably well with each other. The measured insertion loss is less than $2 \mathrm{~dB}$, and the return loss is better than $15 \mathrm{~dB}$ within the passband from 1.89 to $2.11 \mathrm{GHz}$ (3-dB FBW of $11 \%)$. Moreover, the measured rejection levels are over $14 \mathrm{~dB}$ at lower stopband from 0 to $1.87 \mathrm{GHz}$ and better than $15 \mathrm{~dB}$ at upper stopband from 2.19 to $5 \mathrm{GHz}$. The performance comparisons with several reported BPFs are shown in Tab. 1.

\section{Conclusion}

A high-selectivity BPF based on two merged ring resonators has been presented in this paper. Due to the characteristics of the ring structure, six transmission zeros are generated. Through analysis and calculation procedure of S-parameters and TZs, the location of TZs is determined by the formula derivation. It is of most importance that the location of TZs is adjustable with change of microstrip line width, which provides an additional measure to narrow the bandwidth of filter and improve the performance at the stopband. However, the presented structure provides the improved performance in the stopband with the relatively more occupation. However, the size of this filter is hardly decreased due to the width of the microstrip line with $\lambda_{\mathrm{g}} / 2$ length in the middle. It is difficult to obtain more compact structure by folding the microstrip lines without effecting the frequency response. The proposed BPF can offer an alternative design idea for the application in the modern $\mathrm{RF}$ and wireless communication systems.

\section{Acknowledgments}

This work was supported in part by the FY2019 Japan Society for the Promotion of Science (JSPS) Postdoctoral Fellowship for Research in Japan under Grant P19350 and in part by the Grant-in-Aid for JSPS Research Fellow under Grant JP19F19350.

\section{Rreferences}

[1] XU, K. D., ZHANG, F. Y., LIU, Y. H., et al. High selectivity seventh-order wideband bandpass filter using coupled lines and open/shorted stubs. Electronic Letters, 2018, vol. 54, no. 4, p. 223-225. DOI: 10.1049/el.2017.4233

[2] XU, K. D., LI, D. H., LIU, Y. H. High-selectivity wideband bandpass filter using simple coupled lines with multiple transmission poles and zeros. IEEE Microwave and Wireless Components Letters, 2019, vol. 29, no. 2, p. 107-109. DOI: 10.1109/LMWC.2019.2891203

[3] SAlleh, M. K. M., PRigent, G., Pigaglio, O., et al. Quarter-wavelength side-coupled ring resonator for bandpass filters. IEEE Transactions on Microwave Theory and Techniques, 2008, vol. 56, no. 1, p. 156-162. DOI: 10.1109/TMTT.2007.912167

[4] FENG, W. J., GAO, X., CHE, W. Q., et al. Bandpass filter loaded with open stubs using dual-mode ring resonator. IEEE Microwave
Wireless Components Letters, 2015, vol. 25, no. 5, p. 295-297. DOI: 10.1109/LMWC.2015.2410174

[5] GUO, Y. J., XU, K. D., DENG, X. J., et al. Millimeter-wave onchip bandpass filter based on spoof surface plasmon polaritons. IEEE Electron Device Letters, 2020, vol. 41, no. 8, p. 1165-1168. DOI: 10.1109/LED.2020.3003804

[6] MITTAL, G., PATHAK, N. P. Spoof surface plasmon polaritons based microwave bandpass filter. Microwave and Optical Technology Letters, 2020, vol. 63, no. 1, p. 51-57. DOI: 10.1002/mop. 32551

[7] FENG, W. J., CHE, W. Q., CHANG, Y. M., et al. High selectivity fifth-order wideband bandpass filters with multiple transmission zeros based on transversal signal-interaction concepts. IEEE Transactions on Microwave Theory and Techniques, 2013, vol. 61, no. 1, p. 89-97. DOI: 10.1109/TMTT.2012.2227785

[8] XU, K. D., ZHANG, F. Y., LIU, Y. H., et al. Bandpass filter using three pairs of coupled lines with multiple transmission zeros. IEEE Microwave and Wireless Components Letters, 2018. vol. 28, no. 7, p. 576-578. DOI: 10.1109/LMWC.2018.2835643

[9] HUANG, Y. J., WEN, G. J., LI, J. Compact and highly-selective microstrip bandpass filter and diplexer using two-stage twist modified split-ring resonators. In 2015 IEEE MTT-S International Microwave Symposium (IMS2015). Phoenix (AZ, USA), 2015, p. 1-4. DOI: 10.1109/MWSYM.2015.7166825

[10] YANG, Q., SHU, M. J., GUO, C., et al. High selectivity wideband bandpass filter based on stepped impedance open stubs loaded ring resonator. AEUE-International Journal of Electronics and Communications, 2020, vol. 126, p. 1-6. DOI: 10.1016/j.aeue.2020.153408

[11] POZAR, D. M. Microwave Engineering. $3^{\text {rd }}$ ed. New York (USA): John Wiley and Sons, 2005. ISBN: 8126510498

[12] HONG, J., LANCASTER M. J. Microstrip Filters for RF/Microwave Applications. $2^{\text {nd }}$ ed. New York (USA): John Wiley and Sons, 2005. ISBN: 9780470408773

[13] ZHANG, P., LIU, L., CHEN, D., et al. Application of a stubloaded square ring resonator for wideband badpass filter design. MDPI Electronics, 2020, vol. 9, no. 1, p. 1-14. DOI: 10.3390/electronics 9010176

[14] NWAJANA, A. O. Circuit modelling of bandpass/channel filter with microstrip implementation. Indonesian Journal of Electrical Engineering, and Informatics, vol. 8, no. 4, p. 696-705. DOI: 10.11591/ijeei.v8i4.2466

[15] HU, S., HU, Y., ZHENG, H., et al. A compact 3.3-3.5 GHz filter based on modified composite right-/left-handed resonator units. MDPI Electronics, 2020, vol. 9, no. 1, p. 1-9. DOI: 10.3390/electronics 9010001

[16] NWAJANA, A. O., DAINKEH, A., YEO, K. S. K. Substrate integrated waveguide (SIW) bandpass filter with novel microstripCPW-SIW input coupling. Journal of Microwaves, Optoelectronics and Electromagnetic Applications, 2017, vol. 16, no. 2, p. 393-402. DOI: $10.1590 / 2179-10742017$ v16i2793

\section{About the Authors ...}

Xiao-yu WENG was born in Henan, China. He received the B.E. degree in Xi'an Jiaotong University, Xi'an, China, in 2020 , where he is currently working toward the M.E. degree. His research interests include RF/microwave components and circuits.

Kai-da XU was born in Zhejiang, China. He received the B.E. and Ph.D. degrees in Electromagnetic Field and 
Microwave Technology from the University of Electronic Science and Technology of China (UESTC), Chengdu, China, in 2009 and 2015, respectively. From 2012 to 2014, he was a Visiting Researcher with the Department of Electrical and Computer Engineering, Duke University, Durham, NC, USA. In 2015, he joined the Department of Electronic Science, Xiamen University, Xiamen, China as an Assistant Professor. From 2016 to 2017, he was a Postdoctoral Fellow with the State Key Laboratory of Millimeter Waves, City University of Hong Kong, Hong Kong. From 2018 to 2019, he was an Honorary Fellow with the Department of Electrical and Computer Engineering, University of Wisconsin-Madison, WI, USA. He was successfully selected into the "Youth Talent Support Program" of Xi'an Jiaotong University (XJTU) in May 2019, and joined the School of Information and Communications Engineering in XJTU in January 2020. Also, he was awarded a fellowship from the Japan Society for the Promotion of Science (JSPS) and joined the Department of Communications Engineering, Graduate School of Engineering, Tohoku University, as the JSPS Fellow in November 2019. He has authored and coauthored over 100 papers in peerreviewed journals and over 40 papers in conference proceedings. He received the UESTC Outstanding Graduate Awards in 2009 and 2015, respectively. He was the recipient of National Graduate Student Scholarship in 2012, 2013, and 2014 from the Ministry of Education, China. Since 2017, he has served as an Associate Editor for both of the IEEE Access and Electronics Letters. He is also an Editorial Board Member of the AEÜ-International Journal of Electronics and Communications. His current research interests include $\mathrm{RF} /$ microwave, mm-wave/THz devices and antenna arrays.

Ying-jiang GUO was born in Sichuan, China. He received the B.E. and Ph.D. degrees in Electronic Engineering from the Sichuan University and University of Electronic Science and Technology in China, Chengdu, China in 2008 and 2018, respectively. From 2011 to 2013, he was with the Huawei Technologies Co., Ltd., where he was involved in the research of $5 \mathrm{G}$ communication prototype design. From 2013 to 2014, he was with the Sichuan Normal University, where he was a lecturer. Since 2018, he has been with Microsystem and Terahertz Research Center in China Academy of Engineering Physics as an assistant research fellow and focuses on the terahertz integrated circuits and communication technologies. He has authored or coauthored over 30 journal and conference papers. He holds over 5 patents in wireless communication. His research interests include the $\mathrm{RF} / \mathrm{microwave} / \mathrm{mm}$-wave integrated circuits, THz modules/antennas, and systems in package.

An-xue ZHANG received the B.S. degree in Electrical Engineering from Henan Normal University in 1996 and the M.S. and Ph.D. degrees in Electromagnetic and Microwave Engineering from Xi'an Jiaotong University in 1999 and 2003, respectively. He is currently a Professor with Xi'an Jiaotong University. His main research fields include antenna and electromagnetic wave propagation, RF and microwave circuit design, and metamaterials.

Qiang CHEN received the B.E. degree from Xidian University, Xi'an, China, in 1986, the M.E. and D.E. degrees from Tohoku University, Japan, in 1991 and 1994, respectively. He is currently Chair Professor of Electromagnetic Engineering Laboratory with the Department of Communications Engineering, School of Engineering, Tohoku University. His primary research interests include antennas, microwave and millimeter wave, antenna measurement and computational electromagnetics. Dr. Chen received the Best Paper Award and Zen-ichi Kiyasu Award in 2009 from the Institute of Electronics, Information and Communication Engineers (IEICE). He served as the Chair of IEICE Technical Committee on Photonics-applied Electromagnetic Measurement from 2012 to 2014, the Chair of IEICE Technical Committee on Wireless Power Transfer from 2016 to 2018, the Chair of Tokyo Chapter of IEEE Antennas and Propagation Society from 2017 to 2018 . He is now the Chair of IEICE Technical Committee on Antennas and Propagation. He is the IEICE Fellow. 